Cite this: Analyst, 2013, 138, 3934

Received 26th September 2012

Accepted 24th December 2012

DOI: $10.1039 / c 2 a n 36393 c$

www.rsc.org/analyst

\section{Rapid recognition of drug-resistance/sensitivity in leukemic cells by Fourier transform infrared microspectroscopy and unsupervised hierarchical cluster analysist‡}

\author{
Giuseppe Bellisola, $\S^{* a b}$ Gianfelice Cinque, $\S^{c}$ Marzia Vezzalini, $\S^{b}$ Elisabetta Moratti, ${ }^{\text {b }}$ \\ Giovannino Silvestri, ${ }^{b}$ Sara Redaelli, $\S^{d}$ Carlo Gambacorti Passerini, ${ }^{d}$ Katia Wehbe $\S^{c}$ \\ and Claudio Sorio $\S^{b}$
}

\begin{abstract}
We tested the ability of Fourier Transform (FT) InfraRed (IR) microspectroscopy (microFTIR) in combination with unsupervised Hierarchical Cluster Analysis (HCA) in identifying drug-resistance/sensitivity in leukemic cells exposed to tyrosine kinase inhibitors (TKIs). Experiments were carried out in a well-established mouse model of human Chronic Myelogenous Leukemia (CML). Mouse-derived pro-B Ba/F3 cells transfected with and stably expressing the human p210 ${ }^{B C R-A B L}$ drug-sensitive wild-type $B C R-A B L$ or the V299L or T315I p210 $10^{B C R-A B L}$ drug-resistant $B C R-A B L$ mutants were exposed to imatinib-mesylate (IMA) or dasatinib (DAS). MicroFTIR was carried out at the Diamond IR beamline MIRIAM where the mid-IR absorbance spectra of individual $\mathrm{Ba} / \mathrm{F} 3$ cells were acquired using the high brilliance IR synchrotron radiation (SR) via aperture of $15 \times 15 \mu \mathrm{m}^{2}$ in sizes. A conventional IR source (globar) was used to compare average spectra over 15 cells or more. IR signatures of drug actions were identified by supervised analyses in the spectra of TKI-sensitive cells. Unsupervised HCA applied to selected intervals of wavenumber allowed us to classify the IR patterns of viable (drug-resistant) and apoptotic (drug-sensitive) cells with an accuracy of $>95 \%$. The results from microFTIR + HCA analysis were cross-validated with those obtained via immunochemical methods, i.e. immunoblotting and flow cytometry (FC) that resulted directly and significantly correlated. We conclude that this combined microFTIR + HCA method potentially represents a rapid, convenient and robust screening approach to study the impact of drugs in leukemic cells as well as in peripheral blasts from patients in clinical trials with new anti-leukemic drugs.
\end{abstract}

\section{Introduction}

Increasing knowledge of the molecular pathogenesis of chronic myelogenous leukemia (CML) has resulted in the development of new therapeutic molecules able to improve the outcome in CML patients. ${ }^{1}$

Imatinib-mesylate (IMA) is the prototype compound of tyrosine kinase inhibitors (TKIs) targeting the abnormal
${ }^{a}$ Azienda Ospedaliera Universitaria Integrata Verona, Department of Pathology and Diagnostics - Unit of Immunology, Policlinico G. Rossi, P.le L.A. Scuro, 10, I-37134, Verona, Italy. E-mail: giuseppe.bellisola@univr.it; Fax: +39 0458027127; Tel: +39 0458027552

${ }^{b}$ University of Verona, Department of Pathology and Diagnostics - General Pathology, Strada Le Grazie, 8, I-37134, Verona, Italy. E-mail: claudio.sorio@ univr.it; marzia.vezzalini@univr.it; elisabetta.moratti@univr.it; giovannino. silvestri@univr.it; Fax:+390458027127; Tel: +390458027688

${ }^{c}$ Diamond Light Source Ltd, Diamond House, Harwell Science and Innovation Campus, Didcot, Oxfordshire, UK. E-mail: gianfelice.cinque@diamond.ac.uk; katia.wehbe@diamond.ac.uk; Tel: +44 (0)1235778410

${ }^{d}$ University of Milano-Bicocca, Department of Clinical Medicine and Prevention, Via Cadore, 48, I-20052 Monza, Monza Brianza, Italy.E-mail: sara.redaelli@unimib.it; carlo.gambacorti@unimib.it; Fax: +39 0392333539; Tel: +3903964488362

$\dagger$ Most data have been presented at the Synchrotron User Meeting 2012, workshop Cell Microbiology: from cancer research to stem cells; 5-6 September 2012, Diamond Light Source, Chilton, Oxfordshire, UK.
† Electronic supplementary information (ESI) available: Fig. S1. The optimization of microFTIR analysis in samples. (a) Two spectra of the same individual cell restricted by $15 \times 15 \mu \mathrm{m}^{2}$ aperture slits (b) were obtained by microFTIR performed consecutively with synchrotron radiation (SR) and globar as the external and internal IR sources, respectively. The second derivatives of these two spectra are shown in (d) where significantly different signal to noise $(S / N)$ values achieved in each spectrum within the 2600-2400 $\mathrm{cm}^{-1}$ interval of wavenumber have also been reported. To improve the quality of the spectra acquired with globar, the aperture slits were set to $50 \times 50 \mu \mathrm{m}^{2}$ (b) and IR signals were collected from larger areas over homogeneous zones within samples. (c) Spectra with similar quality were obtained within the 1300-900 $\mathrm{cm}^{-1}$ interval of wavenumber by microFTIR with SR and with globar allowing the application of algorithms for unsupervised pattern recognition to a wide interval of wavenumber values. Fig. S2. Cumulative fractions of drug-resistant (blue bars) and drug-sensitive (pink and red bars) cells identified by SR microFTIR + HCA in samples (mean of 3 independent experiments). See DOI: $10.1039 / \mathrm{c} 2 \mathrm{an} 36393 \mathrm{c}$

$\S$ These authors share first authorship. 
tyrosine kinase (TK) activity associated with the kinase domain (KD) of Bcr-Abl oncoproteins (p190, p210, or p230 kDa, respectively). Bcr-Abl is the product of the $B C R-A B L$ chimeric fusion gene (the Philadelphia chromosome, $\mathrm{Ph}^{+}$) derived from a reciprocal translocation between the breakpoint cluster region $(B C R)$ gene located on chromosome 22 and the $c-A b l$ gene $(A B L)$ located on chromosome 9 in the multi-potent bone marrow stem cell. The presence of $\mathrm{Ph}^{+}$in CML cells confers growth factor independence and resistance to apoptosis allowing the progressive expansion of leukemic cell populations in the bone marrow during the chronic phase. ${ }^{2}$ IMA has proved to be effective in inducing hematologic and cytogenetic remission in most CML patients. Unfortunately, a significant percentage of them tend to develop both primary and secondary resistance to IMA often leading to treatment failure.

The clinical transition from the chronic to the blast phase is characterised by the high numbers of CML blast cells circulating in the blood with additional point mutations in the Bcr-Abl KD. Those mutations are often associated with more clinically aggressive and drug-resistant phenotypes. ${ }^{3}$ Secondthird generation TKIs such as dasatinib (DAS), ${ }^{4}$ nilotinib, ${ }^{5}$ and bosutinib $^{6}$ have activity against many Bcr-Abl mutants except T315I mutation for which new drug molecules are in the development pipeline., ${ }^{7,8}$

Most popular molecular predictors of drug response in CML patients are the $B C R-A B L$ transcript levels measured by real-time quantitative PCR, the Bcr-Abl KD mutation analysis, and the monitoring of Bcr-Abl activity. ${ }^{9-12}$ Major drawbacks are the poor standardisation and high costs of molecular methods for monitoring patients. Sometimes genome expression profiling is unable to identify reproducible signatures of drugs and/or to predict drug-resistance in CML patients. ${ }^{13}$ Therefore, the development of new reliable and cost-effective methods to obtain rapid and accurate information on the sensitivity of CML cells to TKIs is of great interest.

The present work aims at exploring whether Fourier transform (FT) infrared (IR) microspectroscopy (microFTIR) in combination with methods for pattern recognition, i.e. unsupervised hierarchical cluster analysis (HCA), could represent a new and convenient analytical approach to obtain information on the sensitivity and resistance of CML cells to TKIs. MicroFTIR has the advantage of being a non-destructive, highly sensitive and specific analytical technique to detect molecular changes. In a few seconds it provides specific and spatially resolved biochemical information about molecular constituents within individual cells. ${ }^{\mathbf{1 4 - 1 6}}$ In association with advanced chemometric methods, microFTIR has already shown potential applications in histopathology, cell biology, and cell pharmacology. ${ }^{17-24}$

\section{Methods}

\section{$\mathrm{Ba} / \mathrm{F} 3$ cells}

Experiments with TKIs were carried out in a well-established mouse-derived $\mathrm{Ba} / \mathrm{F} 3$ cell model of human $\mathrm{Ph}^{+} \mathrm{CML}$ consisting of drug-sensitive cells and drug-resistant mutants. ${ }^{25}$

Mouse pro-B Ba/F3 cells (parental, par-Ba/F3) transfected with and stably expressing the human $\mathrm{p} 210^{B C R-A B L}$ drug- sensitive wild-type $B C R-A B L$ (wt-Ba/F3) or the V299L or T315I p210 ${ }^{B C R-A B L}$ drug-resistant $B C R-A B L$ mutants (V299L- and T315I$\mathrm{Ba} / \mathrm{F} 3$, respectively) were grown under sterile conditions in a humidified atmosphere with $5 \% \mathrm{CO}_{2}$ and in the RPMI 1640 medium added with $2 \mathrm{mmol} \mathrm{L}^{-1} \mathrm{~L}$-glutamine, $10 \%$ foetal bovine serum (FBS), and no antibiotic. Parental Ba/F3 was the $B C R-A B L$ negative control cell line used to test the non-specific toxicity of TKIs. A WEHI-B3 conditioned supernatant was added to the RPMI medium $(10 \% \mathrm{v} / \mathrm{v})$ as a source for interleukin 3 (IL-3) which is necessary to grow par-Ba/F3. ${ }^{26}$ Wild-type Ba/F3 cells and V299L- and T315I-Ba/F3 cell mutants were selected and expanded in the RPMI medium with no IL-3. Wild-type Ba/F3 cells are sensitive to the pro-apoptotic actions of both IMA and DAS. The V299L-Ba/F3 cell mutant is sensitive to IMA and resistant to DAS, whereas T315I-Ba/F3 cell mutant is resistant to both IMA and DAS, respectively.

\section{Tyrosine kinase inhibitors (TKIs)}

Imatinib-mesylate (IMA) is the 4-[(4-methylpiperazin-1-yl)methyl]$\mathrm{N}$-[4-methyl-3-[(4-pyridin-3-ylpyrimidin-2yl)amino]-phenyl]-benzamide compound, also known as CGP057148B and STI571 from Novartis Pharma AG, Basel. ${ }^{27}$ IMA was dissolved (w/v) in sterile $\mathrm{H}_{2} \mathrm{O}$ to obtain a $10 \mathrm{mmol} \mathrm{L}^{-1}$ IMA stock solution that is stable at $-20{ }^{\circ} \mathrm{C}$ and in the dark for some weeks. Blocking the binding of ATP to the KD of Bcr-Abl, IMA inhibits the associated TK activity, restores the sensitivity of CML cells to pro-apoptotic factors and induces cell apoptosis.

Dasatinib (DAS), from Bristol-Myers Squibb BMS-354825 (N-(2-chloro-6-methylphenyl)-2-[[6-[4-(2-hydroxyethyl)-1-piperazinyl]-2-methyl-4-pyrimidinyl]amino]-5-thiazole carboxamide monohydrate), is a dual-specific inhibitor of Src and of both active and inactive conformations of Abl. ${ }^{28}$ DAS (17.2 mg) was dissolved in $1.0 \mathrm{~mL}$ of DMSO to obtain a $35.2 \mathrm{mM}$ DAS stock solution and aliquots were stored at $-20{ }^{\circ} \mathrm{C}$.

In time-course experiments with TKIs, $2.5 \times 10^{6} \mathrm{Ba} / \mathrm{F} 3$ cells and mutants suspended in $1.5 \mathrm{~mL}$ of RPMI medium were separately exposed for 24 or 48 hours to $2.0 \mu \mathrm{M}$ IMA or $16.0 \mathrm{nM}$ DAS, respectively. Appropriate control samples (CTRLs) with no added drug or with DMSO diluted in the growth medium (v/v $1 / 2000$ ) as in DAS-treated samples were also prepared. All experiments were performed at least in triplicate.

\section{Sample preparation}

At the end of incubation, a volume of $0.5 \mathrm{~mL}$ of $4 \%$ bufferedparaformaldehyde (PFA) solution was added to $1.5 \mathrm{~mL}$ of $\mathrm{Ba} / \mathrm{F} 3$ cell suspension. Cells were fixed in 1\% PFA for at least $30 \mathrm{~min}$, pelleted by centrifugation (65 $\mathrm{g}$ for $2 \mathrm{~min}$ ) and re-suspended twice in $\mathrm{H}_{2} \mathrm{O}$. A drop $(10 \mu \mathrm{L})$ of each cell suspension was carefully deposited and air-dried on a $50 \times 25 \times 2 \mathrm{~mm} \mathrm{ZnSe}$ polished crystal to obtain an array of sample spots with cells spread in a monolayer as shown in the ESI, Fig. S1(b)..$^{29}$

\section{FTIR absorbance microspectroscopy (microFTIR)}

The IR absorbance spectra were acquired at the Diamond Light Source (DLS, UK) at the B22 IR beamline Multiband Infrared Imaging and Microspectroscopy (MIRIAM). ${ }^{30}$ Two IR sources 
were used: the highest brilliance synchrotron radiation (SR) for single cell analysis and the globar for average measurements on larger areas. In both cases the mid-IR spectral region between $4000 \mathrm{~cm}^{-1}$ and $400 \mathrm{~cm}^{-1}$ was used.

In a typical SR microFTIR experimental setting in transmission modality, we used the Bruker $80 \mathrm{~V}$ interferometer coupled with a Hyperion 3000 Vis-IR microscope equipped with a $36 \times$ magnification objective (N.A. 0.6) and identical condenser optics; a high sensitivity liquid nitrogen cooled Mercury-Cadmium-Telluride (MCT) detector was used in combination with a Ge filter. To acquire the IR absorbance spectra of individual cells, samples were positioned under the objective and the four blade slits of the microscope were restricted to aperture values of $15 \times 15 \mu \mathrm{m}^{2}$ fitting the sizes of a cell (diameter 12-15 $\mu \mathrm{m}$ ). To optimize microFTIR performed with the broadband globar as a more conventional IR source, the average absorbance spectra representative of about 15-20 cells were acquired from several areas of $50 \times 50 \mu \mathrm{m}^{2}$ in sizes within the sample as shown in Fig S1(b). $\neq$ To obtain the necessary signal to noise ratio $(S / N)$ in the spectra a number of 256 scans at a scanner velocity of $40 \mathrm{kHz}$ were performed in continuous mode at a spectral resolution of $4 \mathrm{~cm}^{-1}$ both on the sample and the background (clean ZnSe substrate area). This is equivalent to a spectrum within 60 seconds.

\section{Pre-processing}

Using different functions in OPUS ${ }^{\mathrm{TM}} 6.5$ software (Bruker Optik $\mathrm{GmbH}$, Ettlingen, Germany), atmospheric and water vapour interferences were compensated and background intensity changes were corrected (concave rubberband correction) within the selected $3800-800 \mathrm{~cm}^{-1}$ interval of wavenumber. To minimize the effects of different thickness within and among samples, spectra were pre-processed with vector normalization function and the second derivative spectra were calculated with a simultaneous smoothing based on the Savitzky-Golay algorithm on 9 smoothing points. The signal to noise ratio $(S / N)$ was systematically calculated as the transmission signal versus root mean square value of the noise within the $2600-2400 \mathrm{~cm}^{-1}$ interval of wavenumber.

\section{Supervised analyses}

The number, position and shape of marker peaks were identified and compared in the spectra. The position of two peaks was considered to be significantly shifted when the difference exceeded the value of spectral resolution $\left(>4 \mathrm{~cm}^{-1}\right)$. The second order derivative was analysed in the corresponding absorbance spectra to identify band and sub-band components within marker peaks. They were assigned according to the so called group frequency approach which associates the absorbance of specific functional groups in molecules with well defined vibrational frequencies reported in the literature. ${ }^{31}$ In quantitative analysis we compared the mean values of integral calculated by drawing a straight line between the two frequency limits delimiting the selected marker peak/region.

\section{Unsupervised hierarchical cluster analysis (HCA)}

In hierarchical cluster analysis (HCA) with no assumption, one or more sub-regions within the spectra of a dataset are input to a clustering algorithm that pools them into groups based solely on their similarity to one another. Although the number of groups and the criterion by which similarity is defined (i.e., Euclidean distance) must be chosen, the resulting output is a non-subjective grouping of the spectra. ${ }^{32}$

HCA was applied to one or more selected spectral intervals in the FTIR spectra pre-processed with vector normalization and second derivative. Typically, the $1760-1480 \mathrm{~cm}^{-1}$ interval of wavenumber was selected to recognize the IR pattern of viable and apoptotic cells whereas the $1150-900 \mathrm{~cm}^{-1}$ interval of wavenumber was used to group the spectra according to changes in phosphate signals, respectively. Initially, a standard method merging two spectra with the smallest spectral distance into a cluster was applied to calculate Euclidean distances among the spectra of individual cells. Then, Ward's algorithm was used to calculate spectral distances between this newly created cluster and all the other spectra or clusters. All spectra grouped in each of the two final classes with the highest heterogeneity value were averaged to obtain the representative spectrum of the corresponding final class. ${ }^{33}$

\section{Independent cross-validation of IR data analyses}

We applied immunomethods to measure the degrees of protein phosphorylation and apoptotic processes in Ba/F3 cells of replicate samples. The results were compared with those obtained from IR analyses in the spectra. ${ }^{29}$

To study and compare the expression of Bcr-Abl and the degrees of protein phosphotyrosine, Ba/F3 cell lysates were adjusted to $1.0 \mathrm{mg}$ total protein per $\mathrm{mL}$. Samples $(20 \mu \mathrm{L})$ were separated on $10 \%$ acrylamide/bisacrylamide gel, electroblotted on polyvinylidene difluoride (PVDF) membranes and probed with a mixture of $4 \mathrm{G} 10$ and PY99 anti-phosphotyrosine antibodies (from Upstate Biotechnology, Waltham, and Santa Cruz Biotechnology, Santa Cruz, USA, respectively). After a second incubation with HRP conjugated secondary antibodies, the complex was visualised by enhanced chemiluminescence (ECL detection system, Amersham, NJ, USA). After stripping, the PVDF membrane was incubated with anti-c-Abl sc-887 (Santa Cruz Biotechnology, Santa Cruz, USA) probing Bcr-Abl and antiactin as a control of constitutive protein expression in cells.

The mean percentages of viable and apoptotic Ba/F3 cells were determined by flow cytometric (FC) analysis of fluorescence in cells stained with e-Fluor 450 for Annexin-V (eBioscience, Inc. San Diego, CA, USA) and Propidium Iodide (PI) vital dye as previously reported. ${ }^{29}$ The unsupervised pattern recognition approach resulted cross-validated when the results of HCA and FC analyses were in agreement.

\section{Statistics}

According to the distribution of results, parametric and/or nonparametric statistics were applied to test hypotheses on the 
means and/or the medians, respectively. The $\alpha$ value was set to 0.05 and the level of significant difference to $P<0.05$.

\section{Results}

Representative FTIR absorbance spectra of untreated CTRLS (blue traces) and of $\mathrm{Ba} / \mathrm{F} 3$ cells and mutants exposed for 48 hours to $2.0 \mu \mathrm{M}$ IMA (red traces) are shown in Fig. 1(a), respectively. Some differences between wt- and V299L-Ba/F3 cells exposed to IMA and the corresponding untreated CTRLS can be immediately appreciated within the $1760-1480 \mathrm{~cm}^{-1}$ and 1150-900 $\mathrm{cm}^{-1}$ intervals of wavenumber, respectively. In contrast, the spectra of Bcr-Abl negative par-Ba/F3 cells and of drug-resistant Bcr-Abl mutant T315I-Ba/F3 exposed to IMA are very similar to those of their untreated CTRLs.

Marker peaks within the $3000-2800 \mathrm{~cm}^{-1}$ interval of wavenumber mainly reflect the $\mathrm{N}-\mathrm{H}$ stretching vibration of protein amide $\mathrm{A}\left(\nu_{\max } 3290 \mathrm{~cm}^{-1}\right)$ and amide $\mathrm{B}\left(\nu_{\max } 3060 \mathrm{~cm}^{-1}\right)$, and the anti-symmetric and symmetric $\mathrm{C}-\mathrm{H}$ stretching vibration from $\mathrm{CH}_{3}\left(\nu_{\max } 2956 \mathrm{~cm}^{-1}\right.$ and $\left.\nu_{\max } 2872 \mathrm{~cm}^{-1}\right)$ and $\mathrm{CH}_{2}\left(\nu_{\max }\right.$ $2925 \mathrm{~cm}^{-1}$ and $\nu_{\max } 2853 \mathrm{~cm}^{-1}$ ) groups in lipids, respectively. Within the $1800-900 \mathrm{~cm}^{-1}$ interval of wavenumber we identified and assigned the following spectral components according to the data published in the literature..$^{33-35}$ The shoulder at $\nu_{\max }$ $1740 \mathrm{~cm}^{-1}$ was mainly assigned to the $\mathrm{C}=\mathrm{O}$ stretching vibration of esters in membrane phospholipids although it can also
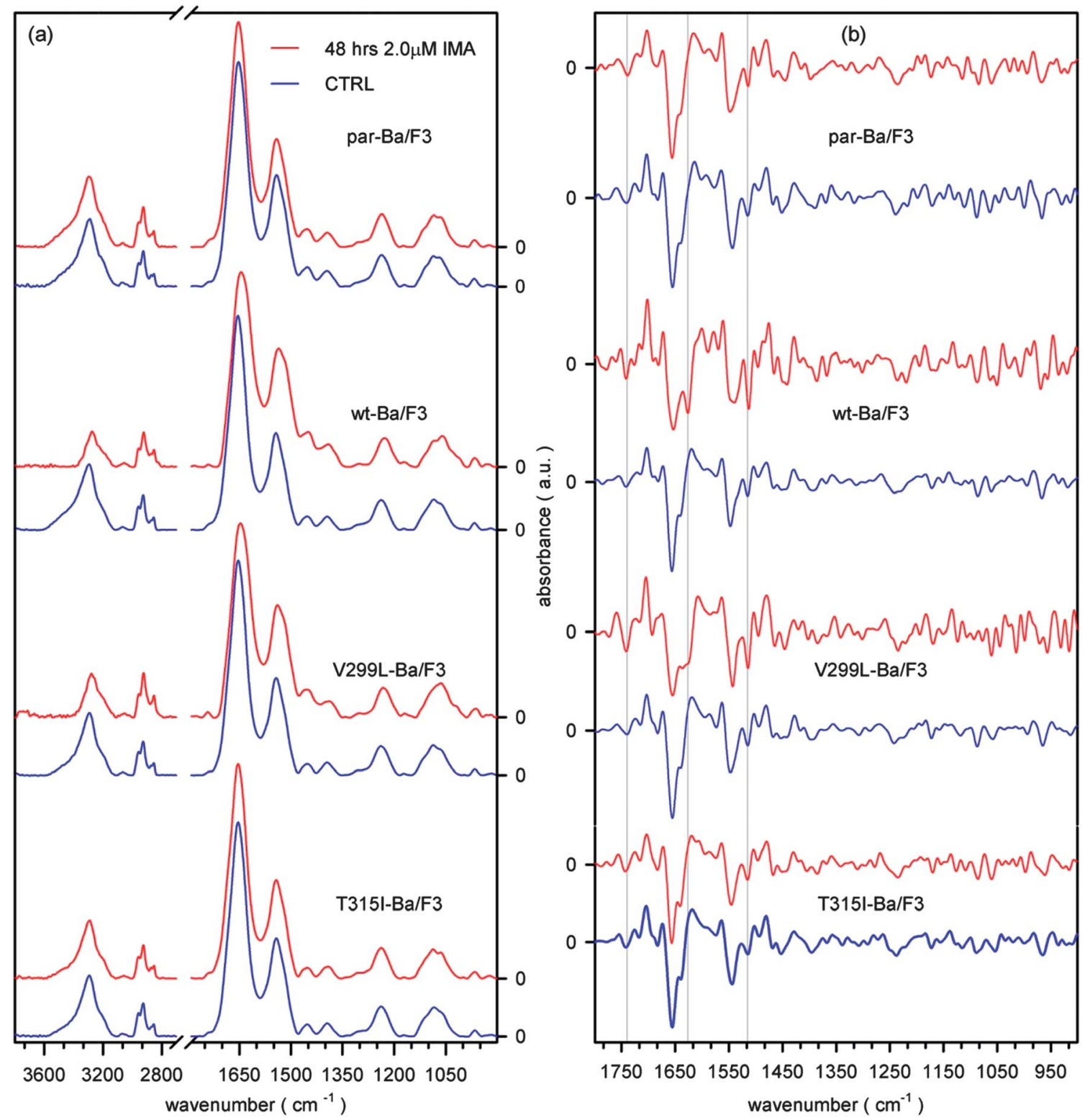

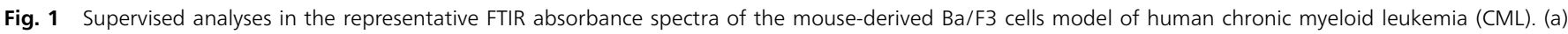

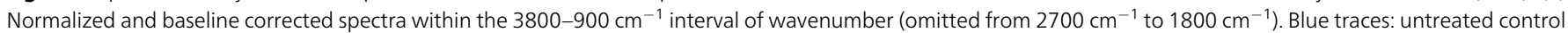

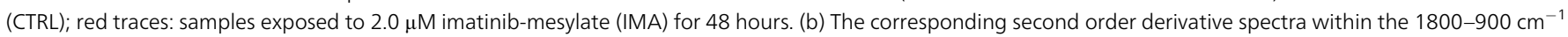
interval of wavenumber. Typical IR signatures induced by IMA have been marked with grey lines. 
reflect changes in the protonation of aspartic and glutamic acid. The most prominent peaks within the $1700-1480 \mathrm{~cm}^{-1}$ interval of wavenumber reflect the absorbance of amide I ( $\nu_{\max } 1650$ $\left.\mathrm{cm}^{-1}\right)$ and amide II $\left(\nu_{\max } 1540 \mathrm{~cm}^{-1}\right)$ in proteins, respectively. The region of amides is sensitive either to the hydration level in sample and to changes in the secondary structures of proteins. To minimise variability related to the hydration level, samples were purged with nitrogen. In addition the interference of free water was subtracted from the spectra by an appropriate algorithm allowing us to compare changes in the secondary structures of proteins among samples. In particular, $\alpha$-helical structures contribute with a component at $\nu_{\max } 1650 \mathrm{~cm}^{-1}$, aggregated $\beta$-sheet structures absorb at $\nu_{\max } 1628 \mathrm{~cm}^{-1}$, and tyrosine residues in proteins have a component at $\nu_{\max } 1512$ $\mathrm{cm}^{-1}$. The anti-symmetric scissoring of $\mathrm{CH}_{3}$ in lipids and proteins and the $\mathrm{C}=\mathrm{O}$ stretching vibrations of $\mathrm{COO}-$ in fatty acids and amino acid side chain absorb at $\nu_{\max } 1450 \mathrm{~cm}^{-1}$ and at $\nu_{\max } 1400 \mathrm{~cm}^{-1}$, respectively. The two major absorbance peaks within the $1300-1000 \mathrm{~cm}^{-1}$ interval of wavenumber originate from the anti-symmetric $\left(\nu_{\max } 1240 \mathrm{~cm}^{-1}\right)$ and symmetric $\left(\nu_{\max } 1086 \mathrm{~cm}^{-1}\right)$ stretching of $\mathrm{PO}_{2}^{-}$groups in nucleic acids DNA and RNA. However, also other phosphate groups such as COP in phospholipids $\left(\nu_{\max } 1086 \mathrm{~cm}^{-1}\right)$ as well as the vibrations of $\mathrm{CH}_{2} \mathrm{OH}$ groups $\left(\nu_{\max } 1056 \mathrm{~cm}^{-1}\right)$ and of $\mathrm{COH}$ groups $\left(\nu_{\max } 1020 \mathrm{~cm}^{-1}\right)$ in carbohydrates may contribute to the shape of marker peaks with limits $1140-990 \mathrm{~cm}^{-1}$. The stretching vibrations of CC and CO functional groups in the deoxyribose and phosphate moieties of the DNA backbone have been reported to occur also at $\nu_{\max } 965 \mathrm{~cm}^{-1}$ whereas the small peaks at $\nu_{\max } 950 \mathrm{~cm}^{-1}$ and at $\nu_{\max } 915 \mathrm{~cm}^{-1}$ have been assigned also to the absorbance of $\mathrm{PO}_{3}{ }^{2-}$ in phosphorylated proteins. Although the univocal interpretation of pre-assigned IR signals cannot be always obtained, the $1800-900 \mathrm{~cm}^{-1}$ interval of wavenumber is generally considered as a "fingerprinting" useful to classify the pattern of individual cells by means of appropriate algorithms.

We optimised a microFTIR setup in order to achieve appropriate signal to noise $(S / N)$ values in the spectra at the necessary spatial resolution (ESI, Fig. S1 $\neq$ ). In fact, the high flux of IR photons released at the sample plane by the narrowed beam from the highest brilliance SR IR source is within the MCT detector dynamic range and enhances the IR signals from the cell restricted within $15 \times 15 \mu^{2}$ (or lower) aperture slits well above the background noise. Therefore, the $S / N$ value in the SR spectrum of Fig. $\mathrm{S} 1(\mathrm{a}) \ddagger$ results appropriate $(S / N=6500)$ as reported in the corresponding second derivative of Fig. S1(d). $\neq$ In contrast, over the same sample area by the isotropic and broad globar source, lower $S / N$ values are achieved $(S / N=1300)$ in the spectrum Fig. $\mathrm{S} 1(\mathrm{~d}) \neq$ as expected. Lower $S / N$ values increase the uncertainty in revealing and assigning bands and sub-bands, i.e., within the region of phosphate signals, and reduce also the probability to classify spectra by unsupervised HCA correctly. Considering that globar is the conventional IR source for routine applications we optimised microFTIR using a broadband MCT and setting the aperture slits of the microscope to delimit spot areas of $50 \times 50 \mu \mathrm{m}^{2}$ in sizes as shown in Fig. S1(b). $\neq$ Within the $1350-900 \mathrm{~cm}^{-1}$ interval of wavenumber shown in Fig. $\mathrm{S} 1(\mathrm{c}) \neq$ the $S / N$ values calculated in the spectra acquired from $50 \times 50 \mu \mathrm{m}^{2}$ spot areas by globar and from $15 \times$ $15 \mu \mathrm{m}^{2}$ spot areas by SR allowed either the identification and assignment of IR signals by the supervised method as well as the application of unsupervised HCA within this interval of wavenumber.

\section{Supervised identification of IR markers of TKI interference with cell growth processes}

Using the supervised group frequency approach we recognised some typical IR signatures related to apoptotic processes in cells. ${ }^{29,37-43}$ As compared to the untreated CTRL (blue traces), the peaks of amide I and amide II are significantly shifted towards lower wavenumber values in the absorbance spectra of drugsensitive $\mathrm{Ba} / \mathrm{F} 3$ cells and mutants exposed to IMA (red traces of wt-Ba/F3 and V299L-Ba/F3 cells in Fig. 1(a), respectively) whereas they coincide in the spectra of drug-resistant cells (red traces of par-Ba/F3 and T315I-Ba/F3 cells in Fig. 1(a)). Vibrational changes are more evident in the second derivative spectra shown in Fig. 1(b) where both the decreased absorbance of the component assigned to $\alpha$-helical structures $\left(\nu_{\max } 1650 \mathrm{~cm}^{-1}\right)$ and the increased absorbance of the component assigned to aggregated $\beta$-sheet structures $\left(\nu_{\max } 1628 \mathrm{~cm}^{-1}\right)$ as well as changes in the intensity of absorbance of the component at $\left(\nu_{\max } 1512 \mathrm{~cm}^{-1}\right)$ may reflect the fragmentation/rearrangement of cytoskeletal and nuclear proteins as well as of DNA as a consequence of the activation of caspases and endonucleases pathways in apoptotic cells. Those molecular events are associated with structural, morphological and physical changes that mainly contribute to the shifts of amide I normally peaking at $\nu_{\max } 1650 \mathrm{~cm}^{-1}$ and of amide II normally peaking at $\nu_{\max } 1540$ $\mathrm{cm}^{-1}$ in the untreated CTRL towards $\nu_{\max } 1640 \mathrm{~cm}^{-1}$ (or lower) and $\nu_{\max } 1530 \mathrm{~cm}^{-1}$ (or lower) wavenumber values in the spectra of apoptotic cells, respectively. Sometimes cells undergoing apoptosis show more pronounced absorbance values at $\nu_{\max }$ $1740 \mathrm{~cm}^{-1}$ mainly reflecting the increased CO stretching in membrane phospholipids.

We assumed that the spectral features of viable and apoptotic cells could reflect drug-resistance and drug-sensitivity in $\mathrm{Ba} / \mathrm{F} 3$ cells and mutants exposed to TKIs, respectively.

\section{Unsupervised pattern recognition by HCA}

Fig. 2(a)-(c) illustrate the results of unsupervised HCA applied to individual SR FTIR spectra of wt-, V299L-, and T315I-Ba/F3 cells within the $1760-1480 \mathrm{~cm}^{-1}$ interval of wavenumber, respectively. The representative IR patterns of viable cells in untreated CTRLs (blue) and the IR patterns of drug-sensitivity (SENS) and drug-resistance (RES) in the samples of wt-Ba/F3 cells and of V299-L and T315I-Ba/F3 cell mutants exposed for 24 and 48 hours to $16.0 \mathrm{nM}$ DAS (pink) or to $2.0 \mu \mathrm{M}$ IMA (red) are shown in Fig. 2(d)-(f), respectively. The results of a representative experiment of FC analysis to quantify the relative percentages of viable (V) and apoptotic (EA and A) wt-, V299Land T315I-Ba/F3 cells in samples are shown in Fig. 2(g)-(i), respectively. 


\section{wt-Ba/F3 cells}

In the dendrogram of 24 hours cell treatment shown in Fig. 2(a), HCA groups the spectra of $2 \%$ DAS- and of $2 \%$ IMA-treated cells (pink and red bars, respectively) together with the spectra of 98\% untreated CTRL (blue bar) in the first class. The second class contains the spectra of $2 \%$ untreated CTRL (blue bar), $98 \%$ DAS-treated (pink bar) and 98\% IMA-treated (red bar) cells, respectively. These two final classes have a distance of 26.1. Fig. 2(a) shows also the dataset of cells exposed for 48 hours to
TKIs. Here, HCA classifies the spectra of 99\% untreated CTRL, $1 \%$ DAS and 1\% IMA-treated cells in the first class, and of $1 \%$ untreated CTRL, 99\% DAS-treated and 99\% IMA-treated cells in the second class, respectively. The distance between the two classes results 44.6. As compared to the representative average spectra of CTRL wt-Ba/F3 cells (Fig. 2(d), blue traces), the average spectra of DAS- and IMA-treated $\mathrm{Ba} / \mathrm{F} 3$ cells grouped by HCA show the typical IR pattern of apoptotic cells with IR signatures that can be easily identified in the corresponding superimposed second derivative spectra shown in Fig. 2(d)
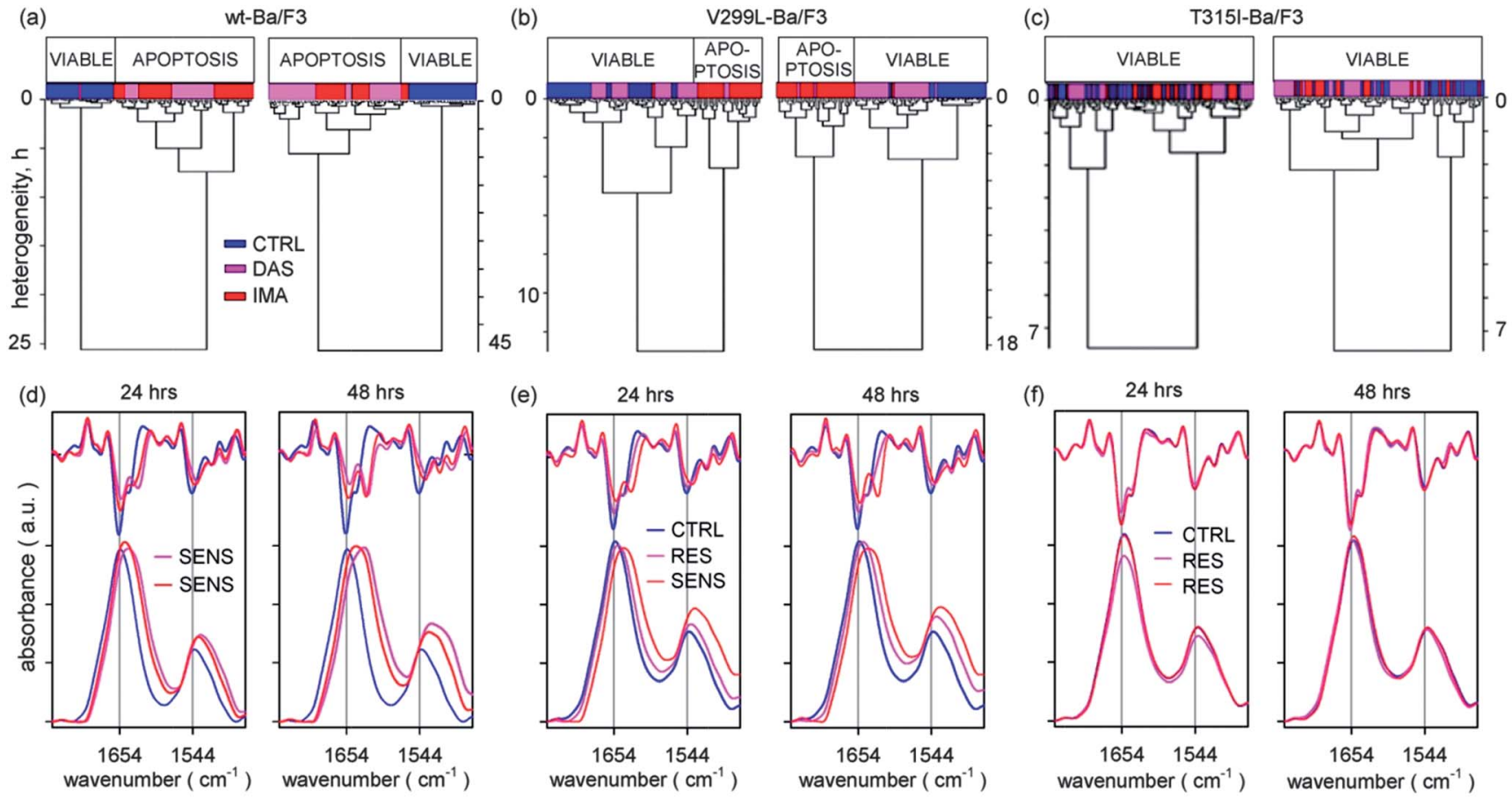

(e)
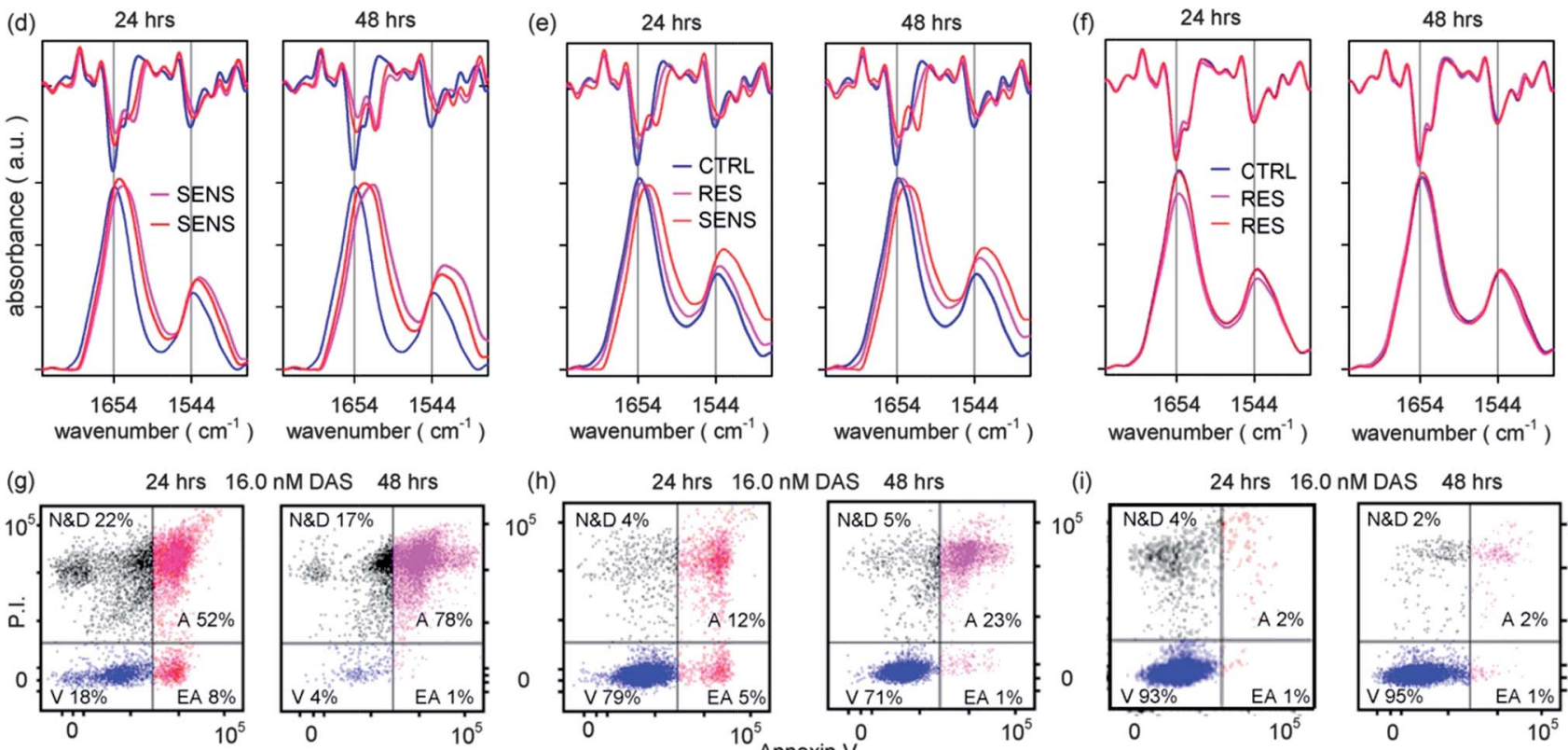

(h)

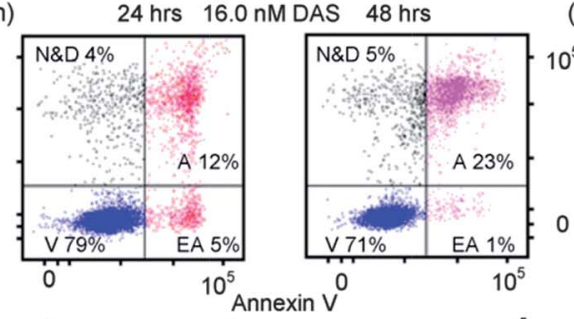

(i)
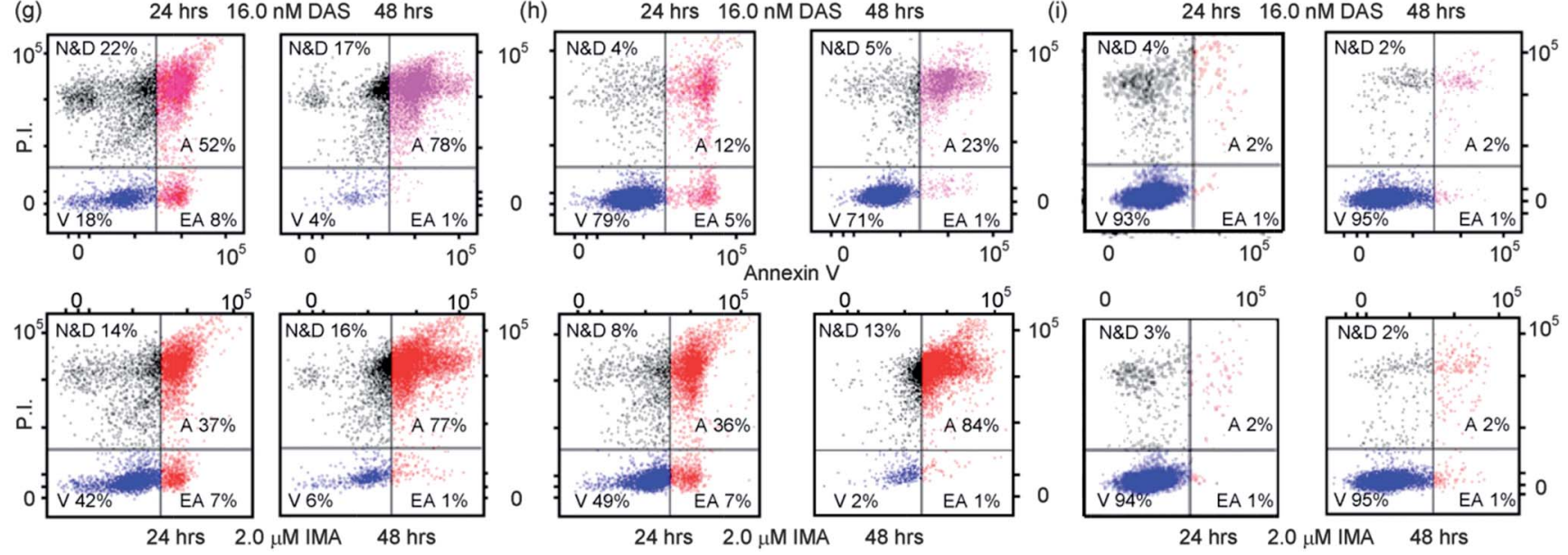

Fig. 2 Unsupervised recognition of IR patterns by hierarchical cluster analysis (HCA) and cross-validation of IR data by flow cytometry (FC) analysis. (a)-(c) The dendrograms with the two final classes resulting from the application of HCA to the SR FTIR absorbance spectra dataset of (a) wt-Ba/F3, (b) V299L-Ba/F3, and (c) T315I$\mathrm{Ba} / \mathrm{F3}$ individual cells in samples exposed for 24 and 48 hours to $16.0 \mathrm{nM}$ DAS (pink bars), or $2.0 \mu \mathrm{M}$ IMA (red bars), and of untreated CTRL samples (blue bars), respectively. (d)-(f) The average spectra representative of each final class in (d) Wt-Ba/F3, (e) V299L-Ba/F3, and (f) T315I-Ba/F3 dataset are shown according to the drugtreatment (blue: untreated CTRL; pink: DAS; red: IMA). Gray lines in the superimposed second derivative spectra highlight differences between the spectra of drugsensitive (SENS) and of drug-resistant (RES) cells. (g)-(i) Representative flow cytometry (FC) analyses performed to measure the relative numbers of apoptotic cells in (g) wt-Ba/F3, (h) V299L-Ba/F3, and (i) T315I-Ba/F3 cell samples exposed for 24 and 48 hours to 16.0 nM DAS (pink) or $2.0 \mu M$ IMA (red), respectively. In each dot-plot of Annexin- $\mathrm{V}$ to Propidium lodide (PI) the fractions of viable cells ( $\mathrm{V}$, blue), of early (EA) and late (A) apoptotic cells (pink and red), and of necrotic cells and debris (N\&D, black) have been reported, respectively. 
within the $1760-1480 \mathrm{~cm}^{-1}$ interval of wavenumber as pink and red traces, respectively. The percentages of viable and apoptotic cells identified by FC analysis and shown in Fig. 2(g) are in agreement with those of HCA.

\section{V299L-Ba/F3 cells}

Most spectra of V299L-Ba/F3 cells exposed for 24 and 48 hours to DAS and shown in Fig. 2(b) as pink bars are grouped by HCA with those of corresponding untreated CTRLs (blue bar) and their representative spectra have very similar IR patterns (pink and blue traces in Fig. 2(e), respectively). In contrast, the spectra of V299L-Ba/F3 cells exposed for 24 and 48 hours to $2.0 \mu \mathrm{M}$ IMA and shown in Fig. 2(b) as red bars are mostly grouped by HCA in distinct classes. In Fig. 2(e) the typical IR markers of cell apoptosis are not present in the representative spectra of DAStreated V299L-Ba/F3 cells resulting therefore with an IR pattern of resistance (RES) to the pro-apoptotic actions of this TKI. In contrast, the spectra of V299L-Ba/F3 cells exposed to IMA show typical IR markers of cell apoptosis and this cell clone results therefore sensitive (SENS) to the actions of this TKI. The results of FC analysis reported in Fig. 2(h) confirm those of HCA.

\section{T315I-Ba/F3 cells}

The spectra of untreated CTRL (blue bars) and of T315I-Ba/F3 mutant cells treated for 24 and 48 hours with $16.0 \mathrm{nM}$ DAS (pink bars) or $2.0 \mu \mathrm{M}$ IMA (red bars) are mixed in the dendrograms of Fig. 2(c). After 24-48 hours T315I-Ba/F3 cells resulted, mostly unaffected by the treatment with TKIs and HCA grouped 57\% untreated CTRL, 2\% DAS-treated, and 51\% IMA-treated T315I$\mathrm{Ba} / \mathrm{F} 3$ cells spectra in the first class and $43 \%$ untreated CTRL, 98\% DAS-treated, and 90\% IMA-treated T315I-Ba/F3 cells spectra in the second class, respectively. According to their double drug-resistance, the representative spectra of T325I-Ba/ F3 cells classified by HCA and shown in Fig. 2(f) have no IR pattern of cell apoptosis and only a few apoptotic cells stained for Annexin-V as illustrated in Fig. 2(i). Significant cell death $(>15 \%)$ was observed in par- and T315I-Ba/F3 cell samples exposed for 48 hours to $32 \mathrm{nM}$ DAS and $8.0 \mu \mathrm{M}$ IMA, respectively. Cumulative fractions of drug-resistant and drug-sensitive $\mathrm{Ba} / \mathrm{F} 3$ cells calculated by SR microFTIR + HCA within replicate experiments are shown in ESI Fig. S2. $\neq$

\section{Supervised identification of IR signatures of TKI interference with protein phosphorylation processes}

TKI treatment induces not only cell apoptosis but also the inhibition of TK activity in sensitive cells. The identification of signatures related to the interferences with abnormal TK activity can therefore represent a valuable tool useful for the early identification of drug-sensitivity/resistance in leukemic blasts.

Fig. 3 illustrates the strategy we used to identify and crossvalidate IR markers of protein phosphorylation in Ba/F3 cells. The intensities of phosphate signals reflected by the mean values of integral with limits $1150 \mathrm{~cm}^{-1}$ and $900 \mathrm{~cm}^{-1}$ in the representative IR spectra are shown in Fig. 3(f). They were related to the expression/activity of Bcr-Abl and to the degrees of protein tyrosine phosphorylation measured in $\mathrm{Ba} / \mathrm{F} 3$ cells and mutants with the different levels of sensitivity to the inhibitory actions of IMA and DAS that are shown in Fig. 3(a) through (d), respectively. To associate the absorbance of phosphorylated proteins with specific intervals of wavenumber $\left(\mathrm{cm}^{-1}\right)$, we compared the FTIR absorbance spectra of equimolar samples of purified bovine serum albumin (BSA) which is not a phosphorylated protein, and of ovalbumin (OVA) and non-fat milk (NFM) which contain various degrees of phosphate rich proteins such as ovalbumin and caseins, respectively. The spectra of reference materials in Fig. 3(e) show absorbance peaks of different intensities within the 1150-700 $\mathrm{cm}^{-1}$ interval of wavenumber. In particular, NFM has the highest and BSA has the lowest absorbance values at $\nu_{\max } 1070$ $\mathrm{cm}^{-1}$, respectively. Therefore we assumed that changes in the intensity of signals within this interval could reflect the different content/degrees of phosphorylated proteins in CML cells. $^{29,35,36}$

To test whether changes within this spectral region were in agreement with the inhibitory actions of IMA and DAS on Bcr$\mathrm{Abl}$ associated TK activity we compared the mean values of integral with limits $1150 \mathrm{~cm}^{-1}$ and $900 \mathrm{~cm}^{-1}$ in the FTIR absorbance spectra of untreated control (CTRL) and of Ba/F3 cells replicates exposed to $16.0 \mathrm{nM}$ DAS or $2.0 \mu \mathrm{M}$ IMA for 24 or 48 hours, respectively. As illustrated in Fig. 3(f), significant differences (mean and standard deviation, SD) are observed among untreated CTRL Ba/F3 cells and among parental- and wt-Ba/F3 cells, and V299L- and T315I-Ba/F3 cell mutants exposed to drugs. In particular the values of this integral reflect those of phosphotyrosine determined by immunoblotting analyses shown in Fig. 3(d). The one way analysis of variance, ANOVA carried out in 3 replicate experiments and 2 time points, revealed that the mean values of this integral were significantly lower in untreated CTRL par-Ba/F3 cells $(2.32 \pm$ $0.035, n=6 ; P<0.001)$ as compared with CTRL wt- $(2.63 \pm$ $0.07)$, V299L- (2.62 \pm 0.11$)$, and T315I-Ba/F3 cells (2.68 \pm 0.08$)$, respectively. Moreover, as compared to the corresponding untreated CTRLs the mean values of this integral were significantly reduced in wt-Ba/F3 cells exposed for 24 and 48 hours to DAS $(2.16 \pm 0.03$ and $1.99 \pm 0.04 ; P<0.001)$ or IMA $(2.18 \pm$ 0.12 and $2.08 \pm 0.05 ; P=0.005)$ and in $\mathrm{V} 299 \mathrm{~L}-\mathrm{Ba} / \mathrm{F} 3$ cells exposed to IMA $(2.2 \pm 0.03$ and $2.13 \pm 0.03 ; P=0.04)$ but not to DAS $(2.54 \pm 0.06$ and $2.51 \pm 0.14)$. According to their double resistance, the values of this integral did not change significantly in the spectra of DAS- and IMA-resistant T315I-Ba/F3 cells. No significant difference was observed also in Bcr-Abl negative par-Ba/F3 cells.

\section{HCA in the spectra obtained by microFTIR with globar}

Fig. 4 illustrates the accuracy of HCA in classifying drug-sensitive and drug-resistant samples within a dataset of spectra acquired by microFTIR with globar.

In the dendrogram of Fig. 4(a), a number of 18 spectra are grouped in the first class, including all untreated CTRLs $(n=8$, blue), all par- and T315I-Ba/F3 treated cells ( $n=8$, black), and DAS-treated V299L-Ba/F3 cells ( $n=2$, black), respectively. Of the 
(a)

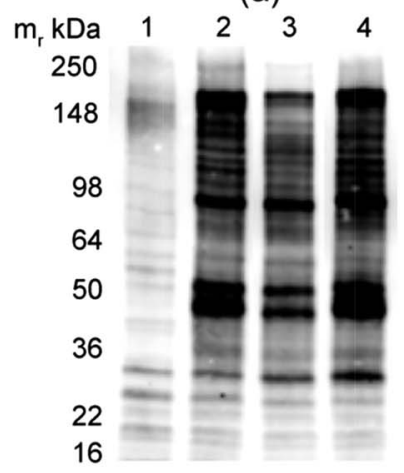

(b)

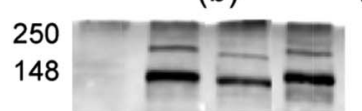

(c)

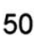

36

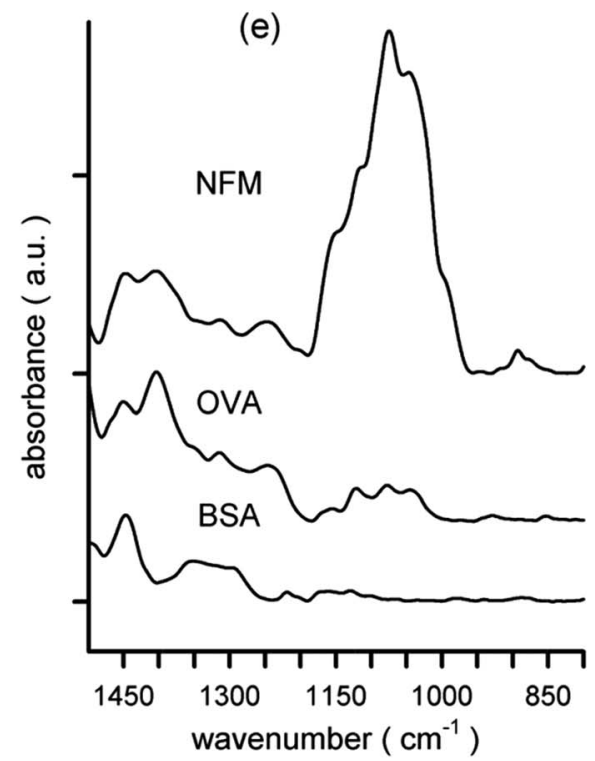

(d)

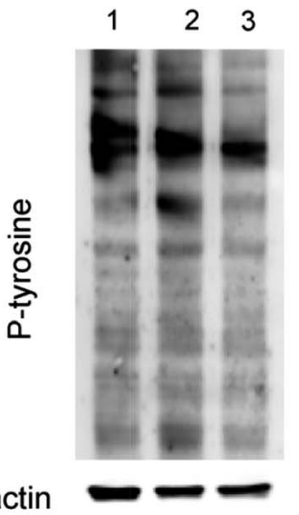

par-Ba/F3

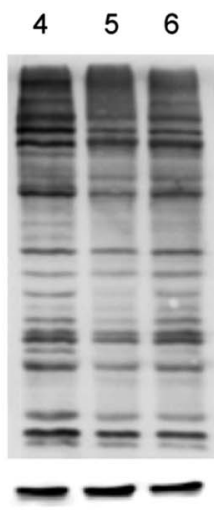

wt-Ba/F3 $\begin{array}{lll}7 & 8 & 9\end{array}$

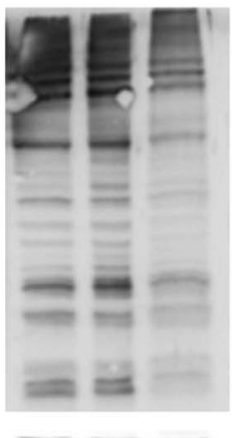

V299L-Ba/F3
$1011 \quad 12$

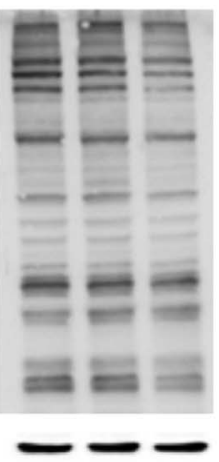

T315I-Ba/F3

(f)

CTRL

24 hrs DAS 24 hrs IMA

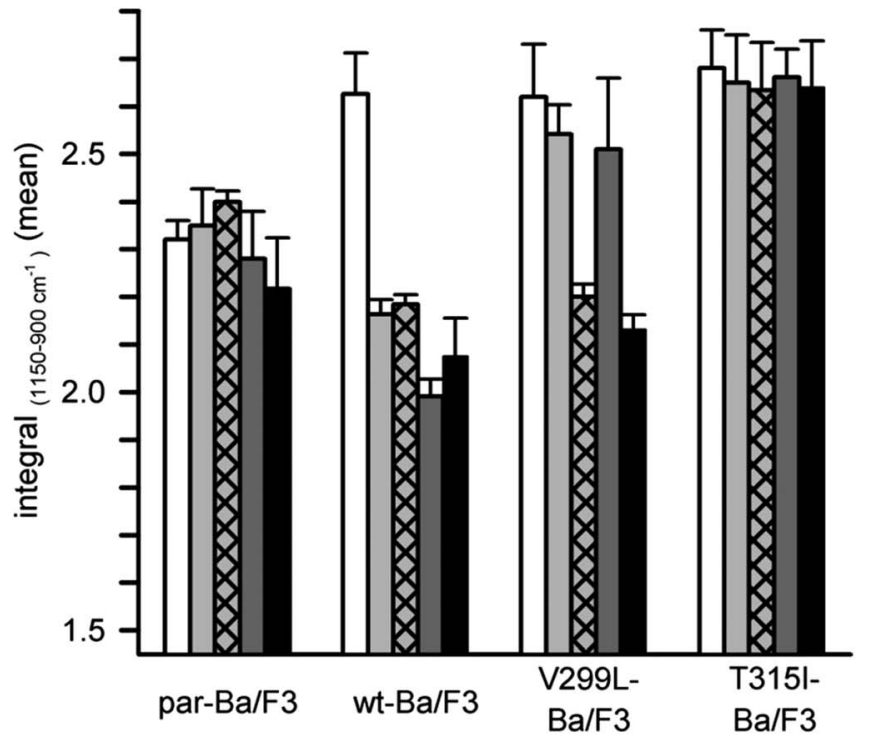

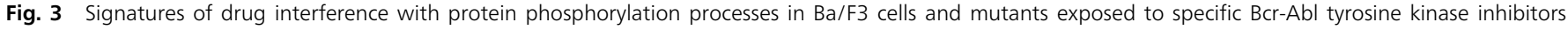

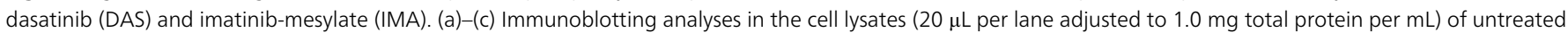

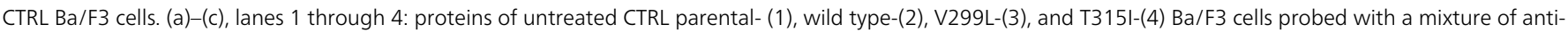

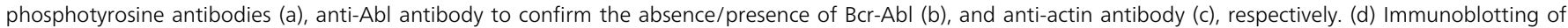

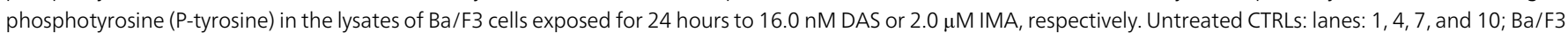

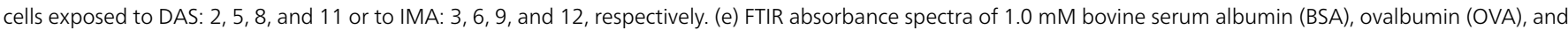

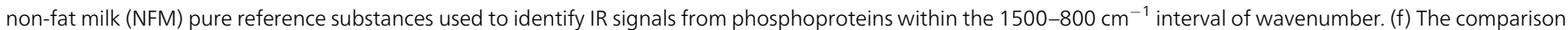
of mean (and error) values of integral with limits $1150 \mathrm{~cm}^{-1}$ and $900 \mathrm{~cm}^{-1}$ calculated in the average spectra of sample replicates $(n=3)$.

remaining 6 spectra grouped in the second class, 4 are those of drug-sensitive wt-Ba/F3 cells exposed for 24 and 48 hours to 16.0 nM DAS or $2.0 \mu \mathrm{M}$ IMA (red), and 2 are of V299L-Ba/F3 cells exposed to IMA for 24 and 48 hours (pink), respectively. The resulting spectra with IR patterns of drug-resistance and drugsensitivity are shown in Fig. 4(b) with major differences highlighted by grey lines. As compared to the spectra of CTRL (blue) and drug-resistant $\mathrm{Ba} / \mathrm{F} 3$ cells (black) samples that were grouped together by HCA, the spectra of DAS-(pink) and IMA-(red) sensitive samples show typical IR markers of cell apoptosis within the $1760-1480 \mathrm{~cm}^{-1}$ interval of wavenumber with additional changes occurring within the $1140-990 \mathrm{~cm}^{-1}$ interval of wavenumber values. In particular, changes at $\nu_{\max } 1056 \mathrm{~cm}^{-1}$ $\left(\mathrm{CH}_{2} \mathrm{OH}\right.$ groups) and at $\nu_{\max } 1020 \mathrm{~cm}^{-1}$ (COH groups) can 


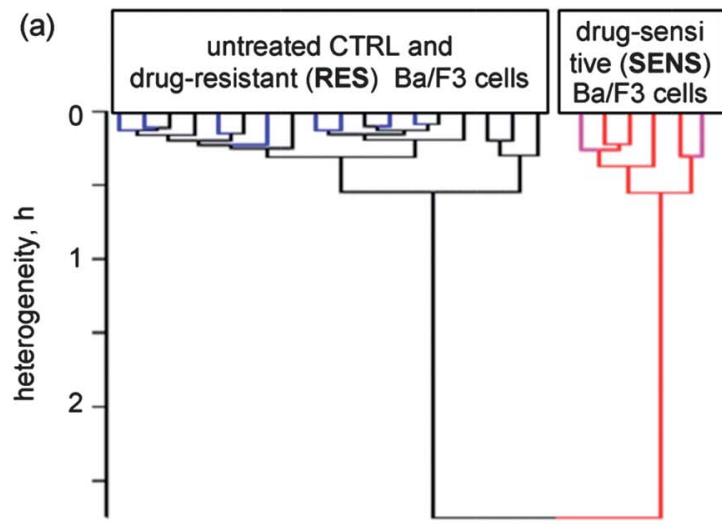

(b)

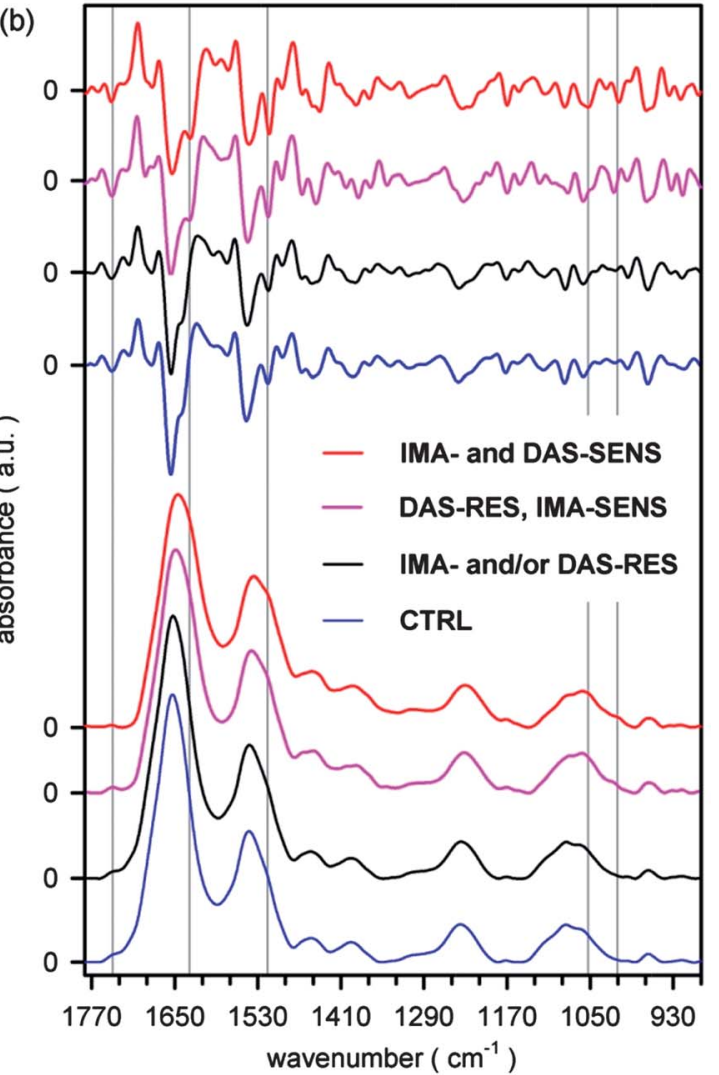

Fig. 4 The unsupervised identification of drug-resistance/sensitivity in samples analysed by microFTIR with globar. (a) HCA of 24 average spectra. (b) Spectral differences between drug-resistant (black) and drug-sensitive (pink and red) samples have been highlighted with gray lines.

suggest some interferences of drugs with the metabolism of carbohydrates, respectively.

\section{Correlation studies}

The results of correlation studies carried out to evaluate whether two independent methods give concordant information are shown in Fig. 5. The dot-plot correlates cell apoptosis quantified in samples by SR microFTIR + HCA $(y)$ and by FC analysis $(x)$, respectively. A direct and significant linear correlation was calculated $(n=50$, Pearson's correlation coefficient $=$

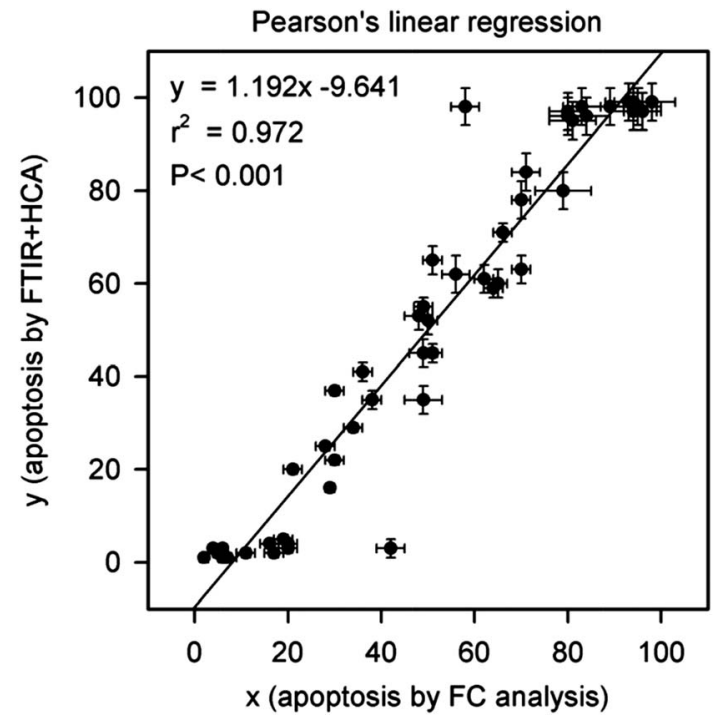

Fig. 5 The correlation among data obtained with two independent methods, SR microFTIR + HCA $(y)$ and FC $(x)$, measuring cell apoptosis in samples (means and errors of triplicates).

0.97) and the line describes the following linear regression equation through data points: $y=1.193 x-9.671$.

\section{Discussion}

The identification of reliable markers of metabolic processes occurring in cells is critical in the field of cell biology and has potential applications in drug discovery and translational medicine. Since the mid-IR spectrum of a cell reflects whole cell biochemistry, microFTIR absorbance spectroscopy is considered a sensitive analytical technique to obtain complete and rapid information on the whole ...omics of cell processes. ${ }^{15,16}$ The possibility of identifying spectral changes reflecting the interference of drugs in cells might suggest the use of the midIR spectrum as a useful biomarker. ${ }^{44,45}$

Analytical methods applied to identify IR signatures of drug actions in the spectra of $\mathrm{Ba} / \mathrm{F} 3$ cells are very similar to those we used to investigate the effect of short exposures (5-240 min) of Bcr-Abl expressing $\mathrm{K} 562$ cells to high doses $(5.0 \mu \mathrm{M}) \mathrm{IMA}^{29}$ In the present work experiments have been carried out in a sophisticated mouse-derived model of human-CML featuring various degrees of response to TKIs in order to more precisely define conditions and parameters necessary to identify drugsensitivity in leukocytes as well as to evaluate the reproducibility and accuracy of the microFTIR + HCA method performed with SR and benchtop globar sources, respectively. It is noteworthy that optimizing experimental conditions of treatment (i.e. incubation time and drug concentrations) and setting IR apertures of the microscope appropriately led to an overlapping capability of SR microFTIR and of microFTIR performed with globar in defining cellular responses to TKIs in the samples. Therefore, the present work has clearly demonstrated the feasibility of applying the microFTIR + HCA method with a benchtop globar source in a clinical setting. 
The simple visual inspection of spectra in Fig. 1 can immediately suggest what samples are sensitive or resistant to drugs. Nevertheless, more appropriate and objective methods are required to perform qualitative and quantitative analyses and to identify subtle differences in the spectra. The acceptable $S / N$ values achieved in the spectra obtained with both SR and globar configurations allow us to perform unsupervised classification by HCA. ${ }^{18,46}$ The major advantage of combining mathematical and statistical methods for multivariate analysis is the suppression of the subjective component to obtain information on drug-resistance/sensitivity in samples. Therefore, the results of the present work have demonstrated that the same accurate identification of drug-sensitive and drug-resistant cells can be obtained by SR microFTIR + HCA (Fig. 2) and, although at lower spatial resolution, also by microFTIR performed with globar (Fig. 4) which is the IR source of first choice for reliable routine microFTIR analyses in samples. MicroFTIR performed with the highest brilliance SR should be preferentially used for validation of reference spectra. ${ }^{\mathbf{4 4}}$

The possibility of combining microFTIR and computational techniques can have several advantages over classic biochemical and immunochemical approaches that are characterized by extended manipulations in the samples. No particular skill and minimal manipulation is required to prepare samples for microFTIR analysis. This reduces the probability of introducing artefacts that can influence the final results. Further advantages derive from the reduction of costly reagents like monoclonal antibodies and fluorescent molecular probes that are extensively used to interrogate the dynamics of cell signalling or the functional status in cells. The potentially high-processivity of microFTIR performed with benchtop instrumentation opens the way to high-throughput screening and further reduction of the costs of individual assays. All these applications, however, rely on the association of IR markers with specific biochemical processes within cells. This implies the initial application of rigorous cross-validation procedures in order to associate specific changes in the IR spectra with a unique or limited set of biochemical, structural, and functional cellular events.

The results of IR analysis in the Ba/F3 cell model of human CML are in agreement with our previous findings obtained in human $B C R-A B L$ positive cell lines exposed to TKIs. ${ }^{29}$ Moreover, the typical IR signatures of cell apoptosis in wt-Ba/F3 cells and sensitive mutants are the same that have been already reported in different cell lines. ${ }^{37-43}$ Not only we have quantified cell apoptosis in samples by SR microFTIR + HCA but also we made the cross-validation of IR signatures to use as potential references in future pre-clinical and clinical applications.

The IR spectra of purified molecules or of their mixtures have already been used to compare and assign vibrational components by a supervised frequency approach in the analysis of IR spectra. ${ }^{35,47}$ As the dynamics of cellular phosphorylation events are crucial to control cell signalling we have focused part of our efforts on this aspect. Using appropriate cellular models suited for the purpose we were able to unequivocally associate and cross-validate some modification within the phosphate region of the mid-IR spectrum with a specific biochemical event involving protein tyrosine phosphorylation (Fig. 3). Another important aspect concerns with the capability of measuring apoptotic/necrotic events associated with the effectiveness of drugs used.

Cell apoptosis is characterized by a sequence of biochemical modifications associated with defined metabolic, structural and morphological changes in cells. ${ }^{48}$ Biochemical events include the release of cytochrome $\mathrm{c}$, the activation of caspases and endonucleases pathways, changes in the outer membrane of mitochondria, the degradation of cytoskeletal and nuclear membrane proteins, the fragmentation of chromatin and internucleosomal DNA, the activation/release of proteolytic enzymes from lysosomes, the generation of reactive oxygen species, and the exposure of phosphatidylserine on the outer plasma membrane. Initially these biochemical and molecular events are associated with cytoplasm shrinkage and chromatin condensation and later progress towards nuclear fragmentation, membrane blebbing and, in ex vivo cell culture systems, the formation and release of apoptotic bodies. These changes contribute to modify the cell size, morphology and optical density of the nucleus and of other intra-cellular organelles and probably induce Mie-type scattering and dispersion artefacts in microFTIR absorbance spectra. ${ }^{49}$ Distortion effects can be observed in the spectral region of amide I and amide II which is often used to characterize changes in protein conformation ${ }^{34}$ and are particularly evident in the SR FTIR spectra of single cells. Therefore the significant shifts of amide I and amide II bands observed in the spectra of drug-sensitive Ba/F3 cells are most probably due to Mie scattering and resonant Mie scattering effects arising from morphological, structural, and physical changes reflecting early and late apoptotic events in those cells. There are many spatiotemporal molecular biomarkers available for the identification of dead and dying cells. $^{50}$ The choice of most appropriate marker(s) is of crucial importance because the timing of those biochemical events often differ, depending upon a wide variety of factors such as the cell line and the cell clone, the pro-apoptotic inducing agent, the concentration of drug or the intensity of stimulus, as well as the time of exposure. Therefore, typical IR shifts we have described in the present work can assume the role of additional useful markers to monitor cell apoptosis.

Several drug screening protocols rely on the inhibition of cell growth and the induction of cell death to select drug candidates to advance towards the drug-discovery pipeline. For example, National Cancer Institute protocols for the preliminary in vitro screening expose three human cancer cell lines to a single dose of new drug for 48 hours. If the growth of one or more cell lines is inhibited, the drug molecule is then probed against the full panel of 60 human cancers. On a yearly basis, only $2 \%$ of approximately 2500 tested compounds usually progress to the next stage of evaluation in mice (http://www.cancer.gov/ cancertopics/factsheet/NCI/drugdiscovery). It is evident that any improvement can bring to higher throughput has an impact into making this approach more cost/effective.

The results of the present study suggest that two critical parameters of interest in drug screening/testing can be evaluated within the IR spectrum: cell death and the levels of phosphorylation in proteins. As the mid-IR spectrum can reveal both 
events, microFTIR performed in samples subjected to a simple processing and within a single round of measurement appears advantageous in comparison with analytical methods that evaluate only one of these parameters at a time (typically cell proliferation/death). Furthermore, such events can be studied at the single-cell level or at a wider cell population level according to the instrument setting chosen.

\section{Conclusions}

The microFTIR + HCA approach described in the present paper is well suited for a drug screening program based on the identification of TKI/phosphatase activators. Being able to identify also the signature of cell death, it can be applied to a much wider range of compounds and cellular models of disease. Since microFTIR analysis does not destroy the sample, and the measurement can be performed on formalin-fixed then dried cells, there is no room for additional significant biochemical alteration after drug treatment. Therefore, samples can also be sent to different facilities/labs for multi-centric evaluation and protocol standardization.

In conclusion, this combined microFTIR + HCA approach requiring minimal sample handling potentially represents a convenient and robust screening approach to identify drugresistance/sensitivity in leukemic cell lines as well as in leukemic blasts from peripheral blood of patients.

\section{Acknowledgements}

The research leading to the results presented in this paper has received funding from the European Community's $7^{\text {th }}$ Framework Programme (FP7/2007-2013) under grant agreement no. 226716 and from Associazione Italiana per la Ricerca sul Cancro (AIRC): IG 4667 to C.S. Regione Lombardia, FSE, Dote ricercatori, ID 16-AR funded S.R. We thank Diamond Light Source for the beamtime assigned to proposals SM-6675 and SM-7143 (Principal Investigator G.B.), as well as Dr Mark Frogley, Dr Jakob Filik and Dr Jacek Pijanka for their assistance during beamtime at MIRIAM. Novartis Pharma AG and Bristol-Myers Squibb are acknowledged for the gift of imatinib-mesylate and dasatinib, respectively.

\section{References}

1 T. O'Hare, M. W. Deininger, C. A. Eide, T. Clackson and B. J. Druker, Clin. Cancer Res., 2011, 17, 212-221.

2 B. J. Druker, Blood, 2008, 112, 4808-4817.

3 S. Roychowdhury and M. Talpaz, Blood Rev., 2010, 25, 279290.

4 L. J. Lombardo, F. Y. Lee, P. Chen, D. Norris, J. C. Barrish, K. Behnia, S. Castaneda, L. A. Cornelius, J. Das, A. M. Doweyko, C. Fairchild, J. T. Hunt, I. Inigo, K. Johnston, A. Kamath, D. Kan, H. Klei, P. Marathe, S. Pang, R. Peterson, S. Pitt, G. L. Schieven, R. J. Schmidt, J. Tokarski, M. L. Wen, J. Wityak and R. M. Borzilleri, J. Med. Chem., 2004, 47, 6658-6661.
5 E. Weisberg, P. W. Manley, W. Breitenstein, J. Brüggen, S. W. Cowan-Jacob, A. Ray, B. Huntly, D. Fabbro, G. Fendrich, E. Hall-Meyers, A. L. Kung, J. Mestan, G. Q. Daley, L. Callahan, L. Catley, C. Cavazza, M. Azam, D. Neuberg, R. D. Wright, D. G. Gilliland and J. D. Griffin, Cancer Cell, 2005, 7, 129-141.

6 L. L. Remsing Rix, U. Rix, J. Colinge, O. Hantschel, K. L. Bennett, T. Stranzl, A. Müller, C. Baumgartner, P. Valent, M. Augustin, J. H. Till and G. Superti-Furga, Leukemia, 2009, 23, 477-485.

7 N. P. Shah, Clin. Adv. Hematol. Oncol., 2011, 9, 925-926.

8 C. A. Eide, L. T. Adrian, J. W. Tyner, M. Mac Partlin, D. J. Anderson, S. C. Wise, B. D. Smith, P. A. Petillo, D. L. Flynn, M. W. Deininger, T. O'Hare and B. J. Druker, Cancer Res., 2011, 71, 3189-3195.

9 B. Mitchell and M. Deininger, Leuk. Lymphoma, 2011, 52(suppl. 1), 4-11.

10 G. Gerrard, K. Mudge, P. Foskett, D. Stevens, M. Alikian, H. E. White, N. C. Cross, J. Apperley and L. Foroni, Am. J. Hematol., 2012, 87, 717-720.

11 P. La Rosée, S. Holm-Eriksen, H. Konig, N. Härtel, T. Ernst, J. Debatin, M. C. Mueller, P. Erben, A. Binckebanck, L. Wunderle, Y. Shou, M. Dugan, R. Hehlmann, O. G. Ottmann and A. Hochhaus, Haematologica, 2008, 93, 765-769.

12 S. Soverini, A. Hochhaus, F. E. Nicolini, F. Gruber, T. Lange, G. Saglio, F. Pane, M. C. Müller, T. Ernst, G. Rosti, K. Porkka, M. Baccarani, N. C. Cross and G. Martinelli, Blood, 2011, 118, 1208-1215.

13 S. K. McWeeney, L. C. Pemberton, M. M. Loriaux, K. Vartanian, S. G. Willis, G. Yochum, B. Wilmot, Y. Turpaz, R. Pillai, B. J. Druker, J. L. Snead, M. MacPartlin, S. G. O'Brien, J. V. Melo, T. Lange, C. A. Harrington and M. W. Deininger, Blood, 2010, 115, 315-325.

14 R. Bhargava, Appl. Spectrosc., 2012, 66, 1091-1120.

15 L. Quaroni and T. Zlateva, Analyst, 2011, 136, 3219-3232.

16 L. M. Miller and P. Dumas, Curr. Opin. Struct. Biol., 2010, 20, 649-656.

17 J. Trevisan, P. P. Angelov, P. L. Carmichael, A. D. Scott and F. L. Martin, Analyst, 2012, 137, 3202-3215.

18 R. Bhargava, Anal. Bioanal. Chem., 2007, 389, 1155-1169.

19 K. Z. Liu, M. Xu and D. A. Scott, Br. J. Haematol., 2007, 136, 713-722.

20 J. Babrah, K. McCarthy, R. J. Lush, A. D. Rye, C. Bessant and N. Stone, Analyst, 2009, 134, 763-768.

21 A. Derenne, M. Verdonck and E. Goormaghtigh, Analyst, 2012, 137, 3255-3264.

22 F. Draux, P. Jeannesson, C. Gobinet, J. Sule-Suso, J. Pijanka, C. Sandt, P. Dumas, M. Manfait and G. D. Sockalingum, Anal. Bioanal. Chem., 2009, 395, 2293-2301.

23 R. Gasper, J. Dewelle, R. Kiss, T. Mijatovic and E. Goormaghtigh, Biochim. Biophys. Acta, 2009, 1788, 12631270.

24 C. M. Krishna, G. Kegelaer, I. Adt, S. Rubin, V. B. Kartha, M. Manfait and G. D. Sockalingum, Biopolymers, 2006, 82, 462-470. 
25 S. Redaelli, R. Piazza, R. Rostagno, V. Magistroni, P. Perini, M. Marega, C. Gambacorti-Passerini and F. Boschelli, J. Clin. Oncol., 2009, 27, 469-471.

26 R. Palacios, G. Henson, M. Steinmetz and J. P. McKearn, Nature, 1984, 309, 126-131.

27 P. W. Manley, S. W. Cowan-Jacob, E. Buchdunger, D. Fabbro, G. Fendrich, P. Furet, T. Meyer and J. Zimmermann, Eur. J. Cancer, 2002, 38(suppl. 5), S19-S27.

28 J. S. Tokarski, J. A. Newitt, C. Y. Chang, J. D. Cheng, M. Wittekind, S. E. Kiefer, K. Kish, F. Y. Lee, R. Borzillerri, L. J. Lombardo, D. Xie, Y. Zhang and H. E. Klei, Cancer Res., 2006, 66, 5790-5797.

29 G. Bellisola, M. Della Peruta, M. Vezzalini, E. Moratti, L. Vaccari, G. Birarda, M. Piccinini, G. Cinque and C. Sorio, Analyst, 2010, 135, 3077-3086.

30 G. Cinque, M. Frogley, K. Wehbe, J. Filik and J. Pijanka, Synchrotron Radiation News, 2011, 24, 24-33.

$31 \mathrm{P}$. Lasch and W. Petrich, in Biomedical Applications of Synchrotron Infrared Microspectroscopy. A Practical Approach, ed. D. Moss, RSC Publishing, Cambridge, 2010, ch. 6, pp. 192-225.

32 L. Wang and B. Mizaikoff, Anal. Bioanal. Chem., 2008, 391, 1641-1654.

33 B. Lavine and J. Workman, Anal. Chem., 2010, 82, 46994711.

34 A. Barth, Biochim. Biophys. Acta, 2007, 1767, 10731101.

35 M. Diem, S. Boydston-White and L. Chiriboga, Appl. Spectrosc., 1999, 53, 148a-151a.
36 I. Yousef, J. Bréard, N. Sid Ahmed-Adrar, A. Maâmer-Azzabi, C. Marchal, P. Dumas and F. Le Naour, Analyst, 2011, 136, 5162-5168.

37 H. Y. Holman, M. C. Martin, E. A. Blakely, K. Bjornstad and W. R. McKinney, Biopolymers, 2000, 57, 329-335.

38 K. Z. Liu, L. Jia, S. M. Kelsey, A. C. Newland and H. H. Mantsch, Apoptosis, 2001, 6, 269-278.

39 F. Gasparri and M. Muzio, Biochem. J., 2003, 369(Pt 2), 239-248.

40 N. Jamin, L. Miller, J. Moncuit, W. H. Fridman, P. Dumas and J. L. Teillaud, Biopolymers, 2003, 72, 366-373.

41 U. Zelig, J. Kapelushnik, R. Moreh, S. Mordechai and I. Nathan, Biophys. J., 2009, 97, 2107-2114.

42 L. Di Giambattista, D. Pozzi, P. Grimaldi, S. Gaudenzi, S. Morrone and A. C. Castellano, Anal. Bioanal. Chem., 2011, 399, 2771-2778.

43 S. Machana, N. Weerapreeyakul, S. Barusrux, K. Thumanu and W. Tanthanuch, Talanta, 2012, 93, 371-382.

44 G. Bellisola and C. Sorio, Am. J. Cancer Res., 2012, 2, 1-21.

45 L. B. Mostaco-Guidolin and L. Bachmann, Appl. Spectrosc. Rev., 2011, 46, 388-404.

46 P. Lasch and D. Naumann, Biochim. Biophys. Acta, 2006, 1758, 814-829.

47 E. Benedetti, E. Bramanti, F. Papineschi, I. Rossi and E. Benedetti, Appl. Spectrosc., 1997, 51, 792-797.

48 S. Elmore, Toxicol. Pathol., 2007, 35, 495-516.

49 P. Bassan, H. J. Byrne, F. Bonnier, J. Lee, P. Dumas and P. Gardner, Analyst, 2009, 134, 1586-1593.

50 B. A. Smith and B. D. Smith, Bioconjugate Chem., 2012, 23, 1989-2006. 